\title{
Cavoaortic shunt improves hemodynamics with preserved oxygen delivery in experimental right ventricular failure during left ventricular assist device therapy
}

\author{
Per Vikholm, MD, ${ }^{a}$ Petter Schiller, MD, ${ }^{a}$ Jakob Johansson, MD, PhD, ${ }^{b}$ and Laila Hellgren, MD, PhD ${ }^{\mathrm{a}}$
}

Objective: Right heart failure is a major cause of morbidity and mortality after left ventricular assist device (LVAD) implantation. This study evaluated the approach of a cavoaortic shunt included in the LVAD circuit, which would aim to relieve venous congestion and improve hemodynamics with preserved oxygen delivery during induced right ventricular failure.

\begin{abstract}
Methods: Right ventricular failure was induced by coronary ligation in 10 pigs. An LVAD was implanted and a cavoaortic shunt was created from the right atrium and included in the assist circuit. Hemodynamic measures and blood gas analyses were analyzed. Oxygen delivery and oxygen consumption were estimated.
\end{abstract}

Results: Right atrial pressure decreased from more than $20 \mathrm{~mm} \mathrm{Hg}$ to $17.2 \mathrm{~mm} \mathrm{Hg}$ (14.8-18.4) with the LVAD and to $14.1 \mathrm{~mm} \mathrm{Hg}(11.2-15.5)(P<.01)$ with the LVAD and cavoaortic shunt. Mean arterial pressure increased from $70.9 \mathrm{~mm} \mathrm{Hg}(67.6-79.8)$ to $81.5 \mathrm{~mm} \mathrm{Hg}(70.8-92.6)(P=.02)$ with addition of the shunt into the assist circuit. Cardiac output increased from $3.5 \mathrm{~L} / \mathrm{min}(2.6-4.2)$ to $4.9 \mathrm{~L} / \mathrm{min}(3.5-5.6)(P<.01)$ with cavoaortic shunting. Oxygen delivery with the cavoaortic shunt was $337 \mathrm{~mL} / \mathrm{min}( \pm 70)$ as compared with left ventricular assist alone at $258 \mathrm{~mL} / \mathrm{min}( \pm 52)(P<.01)$. Oxygen consumption was restored during use of the cavoaortic shunt.

Conclusions: A cavoaortic shunt combined with an LVAD during right ventricular failure reduces central venous pressures, increases systemic arterial pressure, and enables increased cardiac output compared with device therapy alone. This was feasible with preserved oxygen delivery. (J Thorac Cardiovasc Surg 2014;147:625-31)

Left ventricular assist device (LVAD) therapy has become an established treatment for end-stage heart failure. ${ }^{1,2}$ In these patients, right ventricular (RV) failure of various degrees is one of the most dreaded complications known to cause significant morbidity and mortality. ${ }^{3,4}$ Today, although efforts have been made, there is a lack of reliable predictors of which patients will have RV failure undergoing surgery. ${ }^{5,6}$ Irrespective of the preoperative condition of the RV, the LVAD implantation is at times a venture inasmuch as the evolution of RV function during surgery is somewhat unpredictable.

Once severe RV failure occurs, the only reliable treatment is the placement of an RVassist device (RVAD). Patients who receive RVADs have poorer prognoses both in short- and long-term perspectives. However, they more commonly have severe RV failure, venous congestion, and end-organ failure preoperatively. ${ }^{3,7}$ We have earlier evaluated a complementary approach to RVAD, the concept of a modified Glenn shunt (superior vena cava to main

\footnotetext{
From the Department of Cardiothoracic Surgery ${ }^{\mathrm{a}}$ and Department of Anesthesiology and Intensive Care, ${ }^{\mathrm{b}}$ Uppsala University Hospital, Uppsala, Sweden.

Disclosures: Authors have nothing to disclose with regard to commercial support.

Received for publication Aug 24, 2012; revisions received Jan 4, 2013; accepted for publication Feb 11, 2013; available ahead of print March 13, 2013.

Address for reprints: Laila Hellgren, MD, PhD, Department of Cardiothoracic Surgery, University Hospital, 75591 Uppsala, Sweden (E-mail: laila.hellgren. johansson@akademiska.se).

$0022-5223 / \$ 36.00$

Copyright (C) 2014 by The American Association for Thoracic Surgery http://dx.doi.org/10.1016/j.jtcvs.2013.02.010
}

pulmonary artery) in experimental RV failure. ${ }^{8}$ This approach was feasible with a positive effect on hemodynamics such as central venous pressures and cardiac output (CO).

However, in cases of elevated pulmonary vascular resistance (PVR), the concept of Glenn is not an option when RV failure occurs during LVAD surgery.

Elevated PVR is present in some LVAD candidates as a consequence of severe and longstanding congestive heart failure. $^{9-11}$ In these patients, the resistance in the pulmonary vascular bed might be even further elevated with prolonged surgery, coagulopathy, and bleeding necessitating transfusion. This viscous circulatory state with increasing PVR during LVAD implantation might result in a situation that requires temporary decompression of both the RV and the pulmonary circulation.

We sought to evaluate a complementary approach to biventricular failure that would aim at properly unloading the $\mathrm{RV}$, relieving central venous congestion, and unloading the pulmonary circulation. We hypothesized that a cavoaortic shunt included in the LVAD circuit would reduce central venous pressures and improve circulation $(\mathrm{CO}$ and mean arterial pressure [MAP]) with maintained oxygen delivery $\left(\mathrm{Do}_{2}\right)$ in acute $\mathrm{RV}$ failure during LVAD therapy.

\section{MATERIAL AND METHODS}

The Uppsala Ethical Committee on Laboratory Animal Research approved the study and all animals received humane care in compliance with the European Convention on Animal Care. 


$$
\begin{aligned}
& \text { Abbreviations and Acronyms } \\
& \mathrm{CaO}_{2}=\text { arterial oxygen content } \\
& \mathrm{CO}=\text { cardiac output } \\
& \mathrm{Do}_{2}=\text { oxygen delivery } \\
& \mathrm{LA}=\text { left atrium } \\
& \mathrm{LV}=\text { left ventricular } \\
& \mathrm{LVAD}=\text { left ventricular assist device } \\
& \mathrm{MAP}=\text { mean arterial pressure } \\
& \mathrm{PaO}_{2}=\text { arterial oxygen partial pressure } \\
& \mathrm{PVR}=\text { pulmonary vascular resistance } \\
& \mathrm{RA}=\text { right atrium } \\
& \mathrm{RV}=\text { right ventricular (ventricle) } \\
& \mathrm{RVAD}=\text { right ventricular assist device } \\
& \mathrm{SaO}_{2}=\text { arterial oxygen saturation } \\
& \mathrm{SvO}_{2}=\text { mixed venous oxygen saturation } \\
& \mathrm{VO}_{2}=\text { oxygen uptake }
\end{aligned}
$$

\section{Anesthesia}

The study comprised 11 pigs of Swedish country breed with a mean weight of $34.9 \mathrm{~kg}( \pm 1.6)$.

Anesthesia was induced by a subcutaneous injection of xylazine (Rompun, $2.2 \mathrm{mg} / \mathrm{kg}$; Bayer A/S, Lyngby, Denmark) and tiletamine/zolazepam (Zoletil, $1006.0 \mathrm{mg} / \mathrm{kg}$; Virbac SA, CarrosCedex, France) and maintained by infusion of a buffered glucose solution carrier (Rehydrex with glucose, $25 \mathrm{mg} / \mathrm{mL}$; Fresenius Kabi AB, Uppsala, Sweden) with ketamine, $30 \mathrm{mg} /$ $\mathrm{kg} / \mathrm{h}$ (Ketaminol Vet $100 \mathrm{mg} / \mathrm{mL}$; Intervet AB, Stockholm, Sweden), fentanyl, $0.04 \mathrm{mg} / \mathrm{kg} / \mathrm{h}$ (Fentanyl $50 \mu \mathrm{g} / \mathrm{mL}$; B Braun Medical AB, Danderyd, Sweden), midazolam, $0.1 \mathrm{mg} / \mathrm{kg} / \mathrm{h}$ (Midazolam Hameln, $1 \mathrm{mg} / \mathrm{mL}$; Algo1Pharma AB, Kista, Sweden), and pancuronium bromide, $0.3 \mathrm{mg} / \mathrm{kg} / \mathrm{h}$ (Pavulon $2 \mathrm{mg} / \mathrm{mL}$; ScheringPlough AB, Stockholm, Sweden).

Body temperature was controlled with a heating pad, aiming for a core temperature of $37^{\circ} \mathrm{C}$.

The pigs were intubated and mechanically ventilated with $21 \%$ oxygen by a Siemens Servo-i ventilator (Maquet GmbH \& Co KG, Rastatt, Germany). Volume-controlled ventilation was used aiming for an arterial $\mathrm{PCO}_{2}$ within the range of 5.0 to $5.5 \mathrm{kPa}$, and a positive end-expiratory pressure of $5 \mathrm{~cm} \mathrm{H}_{2} \mathrm{O}$ was applied. The bladder was catheterized with a silicone catheter.

A catheter was inserted through the right external jugular vein (BD Careflow 17G; Becton-Dickinson AB, Stockholm, Sweden) for central venous pressure, blood sampling, and drug administration. A thermodilution pulmonary artery cathether (BD Criticath Pulmonary Artery/Thermodilution Catheter; Becton-Dickinson) was introduced through the right external jugular vein and advanced to the pulmonary artery for measurements of $\mathrm{CO}$ and mixed venous oxygen saturation $\left(\mathrm{SvO}_{2}\right)$.

A catheter was inserted into the left femoral artery for continuous monitoring of oxygen saturation $\left(\mathrm{PaO}_{2}\right)$, blood gas extraction, and for arterial blood pressure with a pressure transducer (BD Careflow 20G; BectonDickinson).

\section{Surgical Preparation}

A median sternotomy was performed. The pericardium was opened and pericardial stay sutures were placed. The azygos and hemiazygos veins were ligated. Pressure transducer catheters were surgically placed in the right atrium (RA), RV, and the left atrium (LA). The catheters were secured with fine sutures and connected to a monitoring system (Dräger Infinity Delta; Dräger Medical; Lübeck, Germany). Animals were heparinized with 7500 IU once and repeatedly every 2 hours with 5000 IU. The RA was cannulated with a $24 \mathrm{~F}$ venous cannula (Malleable Single Stage Venous Cannula; Edwards Lifesciences, Irvine, Calif), as shown in Figure 1. The left ventricular (LV) apex was cannulated with a $28 \mathrm{~F}$ venous cannula (Malleable Single Stage Venous Cannula; Edwards Lifesciences). A 16F arterial cannula (FemFlex; Edwards Lifesciences) was inserted into the ascending aorta. All cannulas were secured with purse-string sutures. A Bio-Pump flow probe connector (Medtronic, Inc, Minneapolis, Minn) was connected to the RA cannula. The RA and the LV apical cannula were deaired and connected with a Y-connector to the inflow tubing of a preprimed BioPump connector (Medtronic). The aortic cannula was deaired and connected to the outflow tubing of the Bio-Pump connector.

\section{Experimental Protocol}

RV failure was created by subsequent ligation of 4 to 6 branches of the right coronary artery and all visible branches to the RV from the left coronary artery. The RV was further challenged with volume overload achieved by rapid infusion of $2000 \mathrm{~mL}$ HESRA (Baxter AB, Knivsta, Sweden). RV failure was considered present at an RA pressure of $20 \mathrm{~mm} \mathrm{Hg}$ or more.

When the pressure was $20 \mathrm{~mm} \mathrm{Hg}$ or more, the LVAD was started and set to a flow corresponding to the baseline $\mathrm{CO}$ value. The RA cannula was opened and the flow through this cannula was set to one third of total LVAD flow by an adjustable clamp, so that one third of the $\mathrm{CO}$ was shunted from the RA, via the Bio-Pump connector, into the ascending aorta. After 20 minutes of shunting, measurements were made.

\section{Measurements}

The experimental protocol required right heart failure to be established. Data were recorded during 4 time periods: (1) baseline, (2) severe RV failure, (3) LVAD with closed RA cannula, and (4) LVAD and one third of the total CO through the RA cannula (Figure 1).

A 20-minute stabilization period was followed by repeated measurements every minute for 5 consecutive minutes.

Standard lead II electrocardiogram, systemic arterial blood pressure, RA pressure, RV pressure, LA pressure, and pulmonary artery pressure were monitored continuously and recorded. CO was measured, using the thermodilution technique. During LVAD and LVAD with cavoaortic shunting, the total LVAD flow was used as CO. Blood samples were collected at the same time periods for arterial and venous blood gas analysis. Arterial blood gases, hemoglobin concentration, and $\mathrm{SvO}_{2}$ were measured with an ABL 500 Radiometer (Radiometer Medical ApS, Bronshoj, Denmark).

The arterial oxygen content $\left(\mathrm{CaO}_{2}\right)$ was calculated using the formula $\left(0.0138 \times\right.$ hemoglobin $\left.\times \mathrm{SaO}_{2}\right)+\left(0.0031 \times \mathrm{PaO}_{2}\right)$ and the $\mathrm{Do}_{2}$ using the formula $\mathrm{CaO}_{2} \times \mathrm{CO} \times 10 . \mathrm{VO}_{2}$ was calculated using the formula $\mathrm{Vo}_{2}=\mathrm{CO} \times\left(\mathrm{CaO}_{2}-\mathrm{Cvo}_{2}\right)$.

\section{Statistical Analysis}

Nonparametric tests were used inasmuch as normality assumption was subject to question. For hemodynamic measurements such as RA pressure, $\mathrm{RV}$ pressure, LA pressure, MAP, and CO, the value for each animal was the mean of all measurements of each period and data were expressed as medians with $95 \%$ confidence interval. For blood gas analysis, and calculated parameters $\left(\mathrm{CaO}_{2}\right.$ and $\left.\mathrm{Do}_{2}\right)$, data are expressed as means $( \pm \mathrm{SD})$. The Wilcoxon matched pairs signed-rank test was used to compare differences between the periods: baseline, RV failure, RV failure and LVAD without shunt, and RV failure and LVAD with shunt. Statistical calculations were performed with the SPSS statistical package 20.0 (SPSS, Inc, Chicago, Ill).

\section{RESULTS}

All 10 animals survived the study period and constituted the study group. RV failure was achieved in all pigs leading to significantly elevated right-sided filling pressures. 


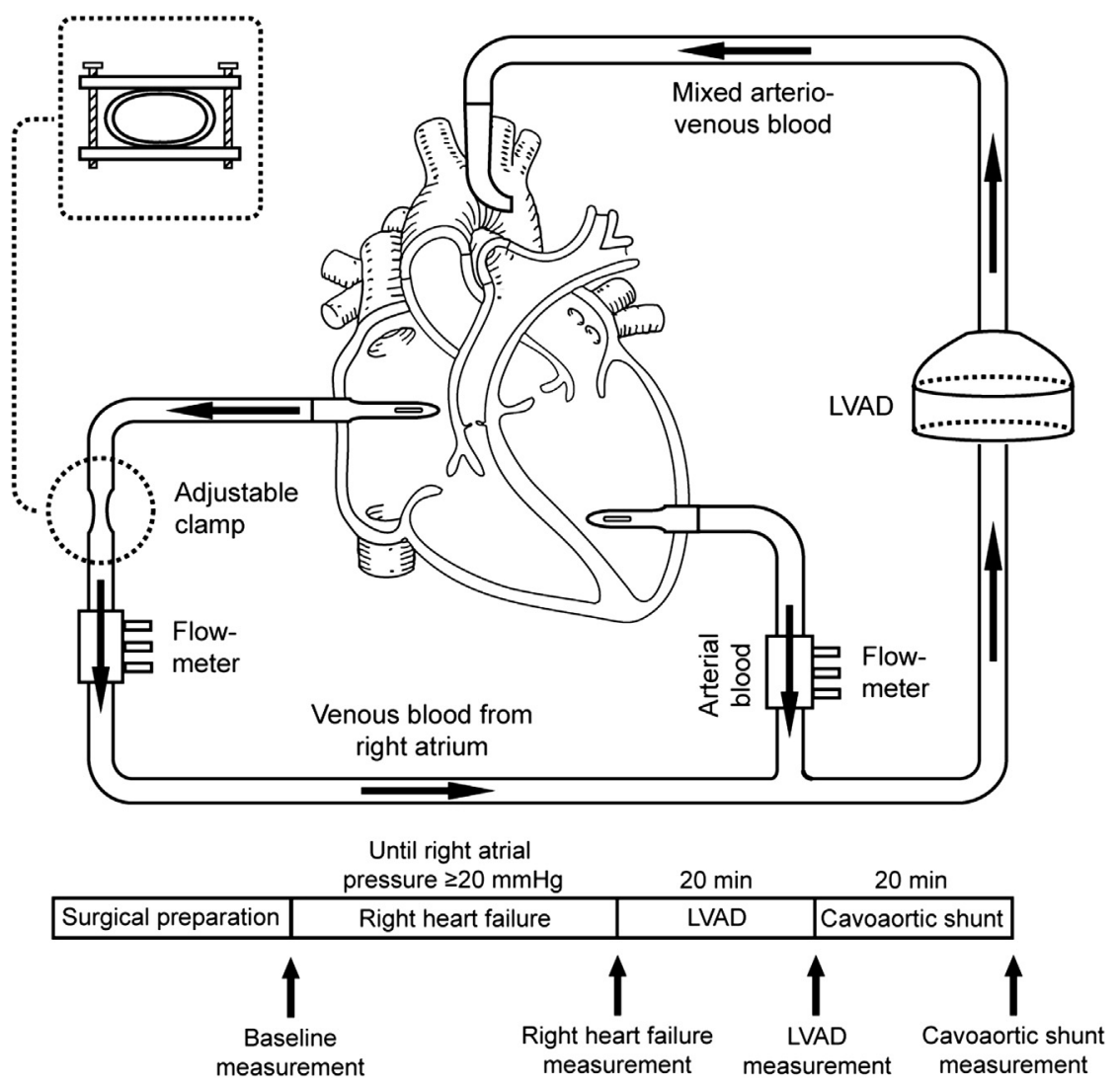

FIGURE 1. Animal preparation and flow chart of the experimental protocol in the model of right ventricular failure in pigs $(n=10)$. An LVAD was implanted and a cavoaortic shunt was created from the right atrium (the cannulas into the superior vena cava) to the aorta. LVAD, Left ventricular assist device.

\section{RV Failure}

After induced RV failure, $\mathrm{CO}$ decreased from $3.4 \mathrm{~L} / \mathrm{min}$ (2.6-4.2) to $2.0 \mathrm{~L} / \mathrm{min}(1.5-2.5)(P=.01$; Table 1$)$. Mean RA pressure increased from $10.8 \mathrm{~mm} \mathrm{Hg}(9.0-11.0)$ at baseline to $20.4 \mathrm{~mm} \mathrm{Hg}(20.0-22.2)(P<.01)$ at RV failure as depicted in Figure 2 and Table 1. The diastolic RV pressure increased from $9.0 \mathrm{~mm} \mathrm{Hg}(8.7-10.3)$ at baseline to 13.4 $\mathrm{mm} \mathrm{Hg}(12.4-16.6)(P<.01$; Figure 2$)$.

No significant changes were observed in the LA pressure or systemic MAP. In addition, the $\mathrm{SaO}_{2}$ and $\mathrm{SvO}_{2}$, remained unchanged during establishment of RV failure (Figure 3). The $\mathrm{Do}_{2}$ was reduced by $43 \%$ from $387 \mathrm{~mL} / \mathrm{min}( \pm 96)$ at baseline to $171 \mathrm{~mL} / \mathrm{min}( \pm 40)(P<.01)$ at $\mathrm{RV}$ failure (Table 1 and Figure 4). Finally, oxygen uptake $\left(\mathrm{VO}_{2}\right)$ was reduced from $180 \mathrm{~mL} / \mathrm{min}( \pm 53)$ to $86 \mathrm{~mL} / \mathrm{min}( \pm 17)$ $(P<.01)$ during $\mathrm{RV}$ failure (Figure 4$)$.

\section{LVAD Therapy Only}

When LVAD therapy was instituted, the pump was set to produce a $\mathrm{CO}$ that was equal to the baseline value at $3.4 \mathrm{~L} /$ $\min (2.6-4.2)$. This resulted in a decrease in RA pressure from $20.4 \mathrm{~mm} \mathrm{Hg}$ (20.0-22.2) to $17.2 \mathrm{~mm} \mathrm{Hg}$ (14.8-18.4) $(P<.01$; Figure 2$)$. Also, the diastolic RV pressure decreased from $13.4 \mathrm{~mm} \mathrm{Hg}(12.4-16.6)$ at $\mathrm{RV}$ failure to
$11.9 \mathrm{~mm} \mathrm{Hg}(11.0-15.0)(P=.02)$ during LVAD therapy, as shown in Table 1 and Figure 2.

Compared with the period with RV failure, MAP was unaffected, but both $\mathrm{Do}_{2}$ and $\mathrm{VO}_{2}$ were increased when LVAD therapy was put in use, as depicted in Table 1.

\section{LVAD and Cavoaortic Shunt}

There was an increase in CO when LVAD therapy was combined with the cavoaortic shunt as compared with LVAD alone, from 3.5 L/min (2.7-4.0) to $4.9 \mathrm{~L} / \mathrm{min}$ (3.55.6) $(P<.01$; Table 1$)$. The RA pressure decreased even further when the cavoaortic shunt was put in use to $14.1 \mathrm{~mm} \mathrm{Hg}$ $(11.2-15.5)(P<.01)$ as compared with LVAD alone (Table 1 and Figure 2). The RV pressures did not change significantly, nor did the LA pressure with use of the shunt. There was an elevation of MAP from $70.9 \mathrm{~mm} \mathrm{Hg}$ (67.6-79.8) with LVAD only to $81.5 \mathrm{~mm} \mathrm{Hg}(70.8-92.6)(P=.02)$ with the use of LVAD and cavoaortic shunt, as described in Table 1.

A decrease in $\mathrm{SaO}_{2}$ from $94.4 \%( \pm 6.4)$ to $86.2 \%( \pm 6.5)$ $(P<.01)$ was observed when the cavoaortic shunt was in use. The $\mathrm{SvO}_{2}$, on the other hand, remained unchanged, as shown in Figure 3 and Table 1 . The $\mathrm{Do}_{2}$ during LVAD and the cavoaortic shunt were higher when compared with LVAD only, at $337 \mathrm{~mL} / \mathrm{min}( \pm 70)$ and $258 \mathrm{~mL} / \mathrm{min}$ 
TABLE 1. Hemodynamic values, blood gas values, and calculations of $\mathrm{CaO}_{2}$ and $\mathrm{DO}_{2}$ at baseline, $\mathrm{RV}$ failure, LVAD treatment, and LVAD treatment plus cavoaortic shunting $(n=10)$

\begin{tabular}{|c|c|c|c|c|c|c|c|}
\hline & Baseline & $\begin{array}{l}\text { Versus } \\
(P \text { value })\end{array}$ & Right heart failure & $\begin{array}{c}\text { Versus } \\
(P \text { value })\end{array}$ & LVAD & $\begin{array}{l}\text { Versus } \\
(P \text { value })\end{array}$ & LVAD plus cavo-aortal shunt \\
\hline $\mathrm{RAP}(\mathrm{mm} \mathrm{Hg})$ & $10.8(9.0-11.0)$ & $<.01$ & $20.4(20.0-22.2)$ & $<.01$ & $17.2(14.8-18.4)$ & $<.01$ & $14.1(11.2-15.5)$ \\
\hline DRVP (mm Hg) & $9.0(8.7-10.3)$ & $<.01$ & $13.4(12.4-16.6)$ & .02 & $11.9(11.0-15.0)$ & .41 & $11.6(10.0-16.0)$ \\
\hline SRVP $(\mathrm{mm} \mathrm{Hg})$ & $31.9(27.8-41.8)$ & .04 & $37.2(35.6-39.2)$ & .17 & $35.7(34.3-43.8)$ & .45 & $35.9(32.2-43.8)$ \\
\hline mPAP $(\mathrm{mm} \mathrm{Hg})$ & $22.4(18.8-24.8)$ & $<.01$ & $28.6(26.4-31.2)$ & .06 & $23.9(21.0-31.4)$ & .72 & $24.0(19.8-34.8)$ \\
\hline $\mathrm{LAP}(\mathrm{mm} \mathrm{Hg})$ & $15.8(13.0-20.0)$ & .11 & $17.2(15.3-26.2)$ & $<.01$ & $13.6(11.0-16.2)$ & .42 & $12.1(10.5-17.8)$ \\
\hline MAP $(\mathrm{mm} \mathrm{Hg})$ & $65.4(60.8-71.8)$ & .07 & $71.7(62.0-79.6)$ & .51 & $70.9(67.6-79.8)$ & .02 & $81.5(70.8-92.6)$ \\
\hline $\mathrm{CO}(\mathrm{L} / \mathrm{min})$ & $3.4(2.6-4.2)$ & $<.01$ & $2.0(1.5-2.5)$ & N/A & N/A & N/A & N/A \\
\hline LVAD (L/min) & N/A & N/A & N/A & N/A & $3.5(2.7-4.0)$ & $<.01$ & $4.9(3.5-5.6)$ \\
\hline $\mathrm{Do}_{2}(\mathrm{~mL} / \mathrm{min})$ & $387( \pm 96)$ & $<.01$ & $171( \pm 40)$ & $<.01$ & $258( \pm 52)$ & $<.01$ & $337( \pm 70)$ \\
\hline $\mathrm{VO}_{2}(\mathrm{~mL} / \mathrm{min})$ & $180( \pm 53)$ & $<.01$ & $86( \pm 17)$ & $<.01$ & $138( \pm 32)$ & .07 & $160( \pm 39)$ \\
\hline $\mathrm{SaO}_{2}(\%)$ & $96.0( \pm 2.2)$ & .51 & $95.2( \pm 3.8)$ & .65 & $94.4( \pm 6.4)$ & $<.01$ & $86.2( \pm 6.5)$ \\
\hline $\mathrm{SvO}_{2}(\%)$ & $50.2( \pm 11.8)$ & .17 & $46.4( \pm 8.2)$ & .84 & $44.2( \pm 6.2)$ & .24 & $44.1( \pm 12.3)$ \\
\hline $\mathrm{CaO}_{2}(\mathrm{~mL} / \mathrm{dL})$ & $11.5( \pm 1.5)$ & $<.01$ & $8.6( \pm 0.9)$ & $<.01$ & $7.5( \pm 0.6)$ & .16 & $7.3( \pm 1.1)$ \\
\hline $\mathrm{CvO}_{2}(\mathrm{~mL} / \mathrm{dL})$ & $6.0( \pm 1.4)$ & $<.01$ & $4.2( \pm 0.9)$ & .02 & $3.5( \pm 0.3)$ & .76 & $3.8( \pm 1.6)$ \\
\hline Hemoglobin $(\mathrm{g} / \mathrm{dL})$ & $8.7( \pm 1.3)$ & $<.01$ & $6.6( \pm 0.8)$ & $<.01$ & $5.8( \pm 0.6)$ & .06 & $6.1( \pm 1.0)$ \\
\hline $\mathrm{PaO}_{2}(\mathrm{kPa})$ & $13.6( \pm 3.2)$ & .39 & $12.9( \pm 2.7)$ & .36 & $12.3( \pm 2.5)$ & $<.01$ & $7.7( \pm 0.9)$ \\
\hline $\mathrm{PaCO}_{2}(\mathrm{kPa})$ & $5.0( \pm 0.5)$ & .42 & $5.1( \pm 0.7)$ & .76 & $5.2( \pm 0.6)$ & .09 & $5.4( \pm 0.8)$ \\
\hline $\mathrm{pH}$ & $7.46( \pm 0.06)$ & .05 & $7.44( \pm 0.06)$ & .30 & $7.43( \pm 0.07)$ & .55 & $7.43( \pm 0.07)$ \\
\hline $\mathrm{SBE}(\mathrm{mmol} / \mathrm{L})$ & $2.9( \pm 2.2)$ & $<.01$ & $1.1( \pm 1.4)$ & .33 & $1.5( \pm 2.0)$ & .04 & $2.0( \pm 2.2)$ \\
\hline
\end{tabular}

Hemodynamic values presented as median with $95 \%$ confidence interval, and blood gas derived values as mean \pm standard deviation. $\mathrm{CaO}_{2}$, Arterial oxygen content; $\mathrm{Do}_{2}$, oxygen delivery; $R V$, right ventricular; $L V A D$, left ventricular assist device; $R A P$, right arterial pressure; $D R V P$, diastolic right ventricular pressure; $S R V P$, systolic right ventricular pressure; $m P A P$, mean pulmonary artery pressure; $L A P$, left atrial pressure; $M A P$, mean arterial pressure; $C O$, cardiac output; $V o_{2}$, oxygen uptake; $S a o_{2}$, arterial oxygen saturation; $\mathrm{SvO}_{2}$, mixed venous oxygen saturation; $\mathrm{CvO}_{2}$, venous oxygen content; $\mathrm{PaO}_{2}$, arterial oxygen partial pressure; $\mathrm{PacO}_{2}$, arterial carbon dioxide partial pressure; $\mathrm{SBE}$, arterial standard base excess; N/A, not applicable.

$( \pm 52)$, respectively $(P<.01$; Figure 4 and Table 1$)$. Moreover, the $\mathrm{VO}_{2}$ was unaffected at $138 \mathrm{~mL} / \mathrm{min}( \pm 32)$ with LVAD only as compared with $160 \mathrm{~mL} / \mathrm{min}( \pm 39)$ when the shunt was in use $(P=.07)$.

\section{Blood Gas Analysis}

Initially, the hemoglobin decreased during the experiment, but then there was a slight increase in hemoglobin during cavoaortic shunting, as shown in Table 1. In addition, the $\mathrm{CaO}_{2}$ decreased throughout the experiment from

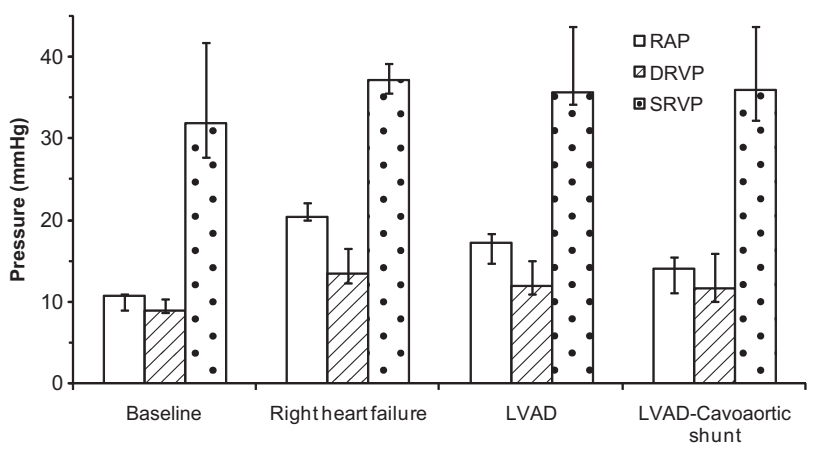

FIGURE 2. Right atrial and right ventricular pressures at baseline, RV failure, LVAD, and LVAD + cavoaortic shunt $(\mathrm{n}=10)$. RAP, Right atrial pressure; $D R V P$, diastolic right ventricular pressure; $S R V P$, systolic right ventricular pressure; $L V A D$, left ventricular assist device.
$11.5 \mathrm{~mL} / \mathrm{dL}( \pm 1.5)$ at baseline to finally $7.3 \mathrm{~mL} / \mathrm{dL}$ $( \pm 1.1)(P<.01)$ with LVAD and use of the cavoaortic shunt, as shown in Table 1. Arterial standard base excess decreased from baseline to RV failure but increased during LVAD to $1.5 \mathrm{mmol} / \mathrm{L}( \pm 2.0)$ and even further when the cavoaortic shunt was used to $2.0 \mathrm{mmol} / \mathrm{L}( \pm 2.2)(P=.03$; Table 1$)$.

\section{DISCUSSION}

This experimental study shows that a cavoaortic shunt combined with LVAD therapy reduces central venous pressure, increases MAP, and enables increased $\mathrm{CO}$ when compared with LVAD without the shunt in a model of induced $\mathrm{RV}$ failure. This was feasible with preserved systemic $\mathrm{Do}_{2}$.

A cavoaortic shunt included in the LVAD circuit increased systemic $\mathrm{Do}_{2}$ by approximately $30 \%$ when compared with LVAD alone in a situation with severe RV failure. The cavoaortic shunt produced a level of $\mathrm{Do}_{2}$ at $87 \%$ of the baseline value as compared with $66 \%$ with LVAD alone. Interestingly, this level of $\mathrm{Do}_{2}$ was accomplished even though nonsaturated blood (shunt flow) was added into the arterial circulation. We believe that the main reason for this increase in $\mathrm{Do}_{2}$ is the increase in $\mathrm{CO}$, which is enabled by the cavoaortic shunt added into the LVAD circuit. This increase in $\mathrm{CO}$ was not possible to obtain without the shunt inasmuch as the failing RV is the limiting factor, unable to increase its workload. Moreover, in a clinical setting, where the $30 \%$ reduction in hemoglobin, which occurred 


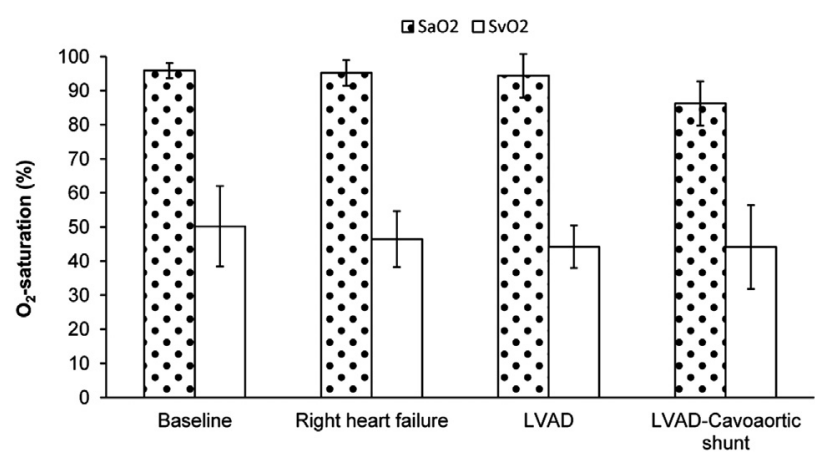

FIGURE 3. Systemic oxygen saturation (arterial and venous) at baseline, right ventricular failure, LVAD, and LVAD + cavoaortic shunt $(\mathrm{n}=10)$. $\mathrm{SaO}_{2}$, Arterial oxygen saturation; $\mathrm{Svo}_{2}$, venous oxygen saturation; $L V A D$, left ventricular assist device.

from baseline to LVAD and shunt could be restored by transfusion, the $\mathrm{DO}_{2}$ with the shunt would most certainly be even further improved. Furthermore, the $\mathrm{SvO}_{2}$ is low but sustained throughout the experiment despite the fact that one third of $\mathrm{CO}$ is shunted directly into the arterial circulation. In addition, $\mathrm{VO}_{2}$ decreases during $\mathrm{RV}$ failure and is restored during LVAD and cavoaortic shunt. Making the assumption that oxygen demand is constant throughout the experiment, this reflects increased tissue oxygenation during shunting.

Consequently, the addition of a cavoaortic shunt into the LVAD circuit enables an increase in $\mathrm{CO}$ and thereby systemic $\mathrm{Do}_{2}$ in a state of severe $\mathrm{RV}$ failure.

An increasing number of studies propose alternative strategies to conventional RVADs. ${ }^{3,4,12-14}$ For example, the use of extracorporeal centrifugal pumps as temporary RVADs is reported more frequently. ${ }^{12,13}$ In our model, the idea is to circumvent the pulmonary circulation to unload the RA and RV, relieve further congestion of the pulmonary vascular bed, and allow adequate filling of the LVAD. In a recent study, a similar concept was evaluated with a bypass from the RA to the LA, ${ }^{15}$ and this shunt could successfully reverse RV failure, increase MAP, and reduce central venous pressures. However, in that experimental

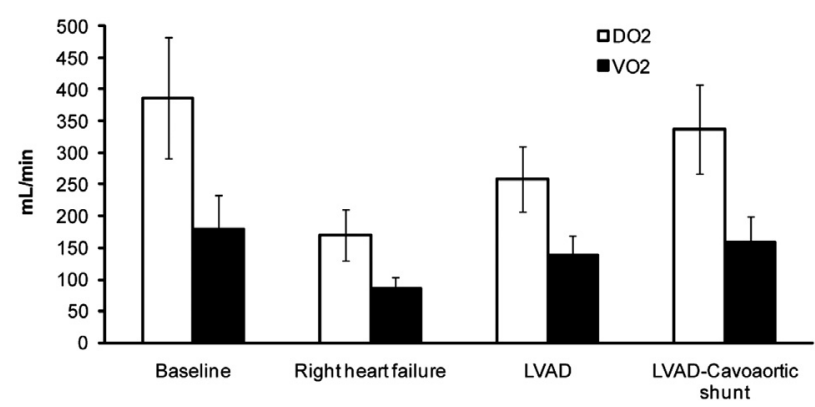

FIGURE 4. Oxygen delivery $\left(\mathrm{Do}_{2}\right)$ and oxygen consumption $\left(\mathrm{Vo}_{2}\right)$ at baseline, right ventricular failure, LVAD, and LVAD + cavoaortic shunt $(\mathrm{n}=10) . L V A D$, Left ventricular assist device. model, the interatrial shunt was not evaluated together with LVAD treatment and the system contained an oxygenator. The inclusion of the shunt into the LVAD circuit adds additional information, which we believe motivates our study. Moreover, Slater and associates ${ }^{16}$ have previously demonstrated the feasibility of right-to-left shunting to reduce right-sided filling pressures in experimental RV failure, also without LVAD treatment. They compared central with peripheral shunting with no statistical difference. They concluded that in a situation with normal pulmonary resistance a shunt of almost $50 \%$ can be tolerated with sustained $\mathrm{SaO}_{2}$. Also, Goldstein and colleagues ${ }^{17}$ conducted a similar study with venoarterial shunting, also with measures of arterial saturation only. However, $\mathrm{SaO}_{2}$ is not a reliable sole indicator of end-organ perfusion, and no estimations of actual systemic $\mathrm{Do}_{2}$ were performed in these studies. Finally, a case report from Toole and coworkers ${ }^{18}$ illustrates a clinical biventricular assist device situation with escalation of pulmonary pressures not responsive to medical management. They successfully used a right-toleft shunt to circumvent the pulmonary circulation.

Although the field of assist device treatment has made great progress over the past 10 years, preoperative RV failure is associated with poor results. Preoperative RV failure reduces survival to transplant in LVAD patients from $85 \%$ to approximately $57 \% .{ }^{10}$ Preoperative prediction of RV failure is still somewhat unreliable, and attempts to develop useful preoperative risk scores are still a struggle. Once present, RV failure is associated with increased perioperative bleeding, more blood transfusions, higher mortality and morbidity, increased incidence of dialysis, worsening of renal and liver function, and increased postoperative lengths of stay. ${ }^{19,20} \mathrm{We}^{8}$ have recently shown improved hemodynamics and reduction of central venous pressures in $\mathrm{RV}$ failure with volume exclusion of the RV with a modified Glenn connection (shunt from the superior vena cava to the pulmonary artery). However, the concept of a Glenn connection in $\mathrm{RV}$ failure requires normal resistance in the pulmonary vascular bed inasmuch as the shunt is not driven mechanically. Thus the Glenn procedure is not an option in patients with increased PVR.

The reestablishment of CO that an LVAD offers without relieving venous congestion may not necessarily avert the clinical state of end-organ failure. There has been a conceptual shift regarding the view of end-organ function in patients with heart failure implying that end-organ function such as liver and kidney is even further worsened by high venous pressures than solely on the impairment of CO. Mullens and associates, ${ }^{21}$ in a study of patients with regular heart failure, showed that preservation of $\mathrm{CO}$ without relieving central venous pressures may not avert development of worsening renal function. The addition of the cavoaortic shunt into the LVAD circuit in our model reduced the central venous pressures even further than use of the LVAD only. In 
RVAD candidates with elevated PVR, it might be difficult to accomplish an adequate reduction of central venous pressures during RVAD treatment. If PVR is even further increased owing to cardiopulmonary bypass and blood transfusion, ${ }^{22}$ the congestion in the pulmonary vascular bed increases and even the RVAD treatment will resolve in suboptimal loading of the LVAD, inasmuch as the transpulmonary blood flow will be the limiting factor. In these desolate cases, a bypass of both the RV and the pulmonary vascular bed might offer a beneficial clinical situation inasmuch as it will unload the pulmonary circulation and thereby relieve further pulmonary congestion. The clinical situation in which a cavoaortic shunt could be of use could be pulmonary dysfunction owing to an increase in PVR (nonresponsive to medical treatment), as described in the previously mentioned case report on a patient with a biventricular assist device. ${ }^{18}$

The major advantage of the cavoaortic shunt included in the LVAD circuit, compared with standard RVAD placement, is the simplicity of its removal. Multiple reoperations in these critically ill patients are preferably avoided. In the setting of biventricular failure after cardiopulmonary bypass, the addition of an RA cannula to the LVAD circuit is a very simple and safe method to decompress the RV without the need to use a separate pump and/or oxygenator. There is no need for cannulation of the RV, which can be technically complicated. When the RV recovers, the clamp on the RA cannula enables controlled weaning and the RA cannula can easily be removed. Furthermore, if the oxygen demand increases, it is simple to insert an oxygenator in the system and thereby provide excellent oxygenation support. Moreover, our findings suggest that current guidelines recommending closing of atrial septal defects to prevent shunting and hypoxia can be discussed. Given the overall poor state of health of the typical LVAD candidate, the shortening of the surgical procedure and bypass time is of importance.

\section{Limitations}

The major limitation of our study is that the long-term patency of the results cannot be secured in this model of acute $\mathrm{RV}$ failure. The effects of shunting on $\mathrm{PaO}_{2}$ and blood $\mathrm{pH}$ may not fully manifest during the time course studied. In addition, the use of pressure-volume loops or echocardiography could have allowed for assessment of RV volumes and loading conditions. The $\mathrm{Do}_{2}$ is a calculated based on $\mathrm{CO}$ and $\mathrm{CaO}_{2}$. A more reliable method to measure the actual perfusion of end organs would secure data regarding the actual state of perfusion.

An additional limitation is that each animal acts as its own control throughout the protocol. This makes the measurements not completely comparable owing to the physiologic changes that might occur in response to the various steps of the protocol. Finally, the cavoaortic approach should be compared and validated to a model with classic RVAD or extracorporeal membrane oxygenation.

In conclusion, a cavoaortic shunt included in the LVAD circuit improved hemodynamics and enabled increased $\mathrm{CO}$, compared with LVAD alone, in an experimental model of RV failure. Moreover, the shunt decreased central venous pressures even further than only LVAD. This approach was feasible with preserved $\mathrm{DO}_{2}$. The concept of a right-to-left shunt included in the LVAD circuit can be used as shortterm support for RV failure when there is a need for RV support in combination with decompression of a congested pulmonary vascular bed.

\section{References}

1. Miller LW, Pagani FD, Russell SD, John R, Boyle A, Aaronson K, et al. Use of a continuous-flow device in patients awaiting heart transplantation. $N$ Engl J Med. 2007;357:885-96.

2. Slaughter MS, Rogers JG, Milano CA, Russell S, Conte J, Feldman D, et al. Advanced heart failure treated with continuous-flow left ventricular assist device. N Engl J Med. 2009;361:2241-51.

3. Dang NC, Topkara VK, Mercando M, Kay J, Kruger KH, Aboodi MS, et al. Right heart failure after ventricular assist device implantation in patients with chronic congestive heart failure. J Heart Lung Transplant. 2006;25:1-6.

4. Deng MC, Edwards LB, Hertz MI, Rowe AW, Keck BM, Kormos R, et al. Mechanical Circulatory Support Device Database of the International Society for Heart and Lung Transplantation: third annual report-2005. J Heart Lung Transplant. 2005;24:1182-7.

5. Matthews JC, Koelling TM, Pagani FD, Aaronson KD. The right ventricular failure risk score a pre-operative tool for assessing the risk of right ventricular failure in left ventricular assist device candidates. J Am Coll Cardiol. 2008;51:2163-72.

6. Drakos SG, Janicki L, Horne BD, Kfoury AG, Reid BB, Clayson S, et al. Risk factors predictive of right ventricular failure after left ventricular assist device implantation. Am J Cardiol. 2010;105:1030-5.

7. Cleveland JC, Naftel DC, Reece TB, Murray M, Antaki J, Pagani FD, et al. Survival after biventricular assist device implantation: an analysis of the Interagency Registry for Mechanically Assisted Circulatory Support database. J Heart Lung Transplant. 2011;30:862-9.

8. Vikholm P, Schiller S, Johansson J, Hellgren L. A modified Glenn shunt improves haemodynamics in acute right ventricular failure in an experimental model. Eur J Cardiothorac Surg. 2013;43:612-8.

9. Elefteriades JA, Lovoulos CJ, Tellides G, Goldstein LJ, Rocco EJ, Condos SG, et al. Right ventricle-sparing heart transplant: promising new technique for recipients with pulmonary hypertension. Ann Thorac Surg. 2000;69:1858-63.

10. Kirklin JK, Naftel DC, Kormos RL, Stevenson LW, Pagani FD, Miller MA, et al. The Fourt INTERMACS Annual Report: 4000 implants and counting. J Heart Lung Transplant. 2012;31:117-26.

11. Mikus E, Stepanenko A, Krabatsch T, Loforte A, Dandel M, Lehmkuhl HB, et al. Reversibility of fixed pulmonary hypertension in left ventricular assist device support recipients. Eur J Cardiothorac Surg. 2011;40:971-7.

12. Scherer M, Sirat AS, Moritz A, Martens S. Extracorporeal membrane oxygenation as perioperative right ventricular support in patients with biventricular failure undergoing left ventricular assist device implantation. Eur J Cardiothorac Surg. 2011;39:939-44.

13. Saito S, Sakaguchi T, Miyagawa S, Nishi H, Yoshikawa Y, Fukushima S, et al. Recovery of right heart function with temporary right ventricular assist device using a centrifugal pump in patients with severe biventricular failure. $J$ Heart Lung Transplant. 2012;31:858-64.

14. Haneya A, Philipp A, Puehler T, Rupprecht L, Kobuch R, Hilker M, et al. Temporary percutaneous right ventricular support using a centrifugal pump in patients with postoperative acute refractory right ventricular failure after left ventricular assist device implantation. Eur J Cardiothorac Surg. 2012;41:219-23.

15. Spillner J, Stoppe C, Hatam N, Amerini A, Menon A, Nix C, et al. Feasibility and efficacy of bypassing the right ventricle and pulmonary circulation to treat right ventricular failure: an experimental study. J Cardiothorac Surg. 2012;7:1-8.

16. Slater JP, Goldstein DJ, Ashton RC, Levin HR, Spotnitz HM, Oz MC. Right-toleft veno-arterial shunting for right-sided circulatory failure. Ann Thorac Surg. 1995;60:978-85. 
17. Goldstein DJ, Ashton RC, Slater J, Pearson M, Seldomridge JA, D'Alessandro DA, et al. Venoarterial shunting for the treatment of right sided circulatory failure after left ventricular assist device placement. ASAIO J. 1997;43:171-6.

18. Toole MJ, Strange RG, Kirker EB, Ikonomidis JS. Novel approach to management of acute pulmonary failure during biventricular assist device insertion. J Heart Lung Transplant. 2009;28:107-9.

19. Oz MC, Argenziano M, Catanese KA, Gardocki MT, Goldstein MT, Goldstein DJ, et al. Bridge experience with long-term implantable left ventricular assist devices. Are they an alternative to transplantation? Circulation. 1997;95: 1844-52.
20. Kavarana MN, Pessin-Minsley MS, Urtecho J, Catanese KA, Flannery M, $\mathrm{Oz} \mathrm{MC}$, et al. Right ventricular dysfunction and organ-failure in left ventricular assist device recipients: a continuing problem. Ann Thorac Surg. 2002;73: 745-50.

21. Mullens W, Abrahams Z, Francis G, Sokos G, Taylor D, Starling G, et al. Importance of venous congestion for worsening of renal function in advanced decompensated heart failure. J Am Coll Cardiol. 2009;53:589-96.

22. Cave AC, Manche A, Derias NW, Hearse DJ. Thromboxane A2 mediates pulmonary hypertension after cardiopulmonary hypertension in the rabbit. $J$ Thorac Cardiovasc Surg. 1993;106:959-67. 